\title{
ABP aplicada ao ensino de engenharia mecânica
}

\section{Vanessa Feliciano Martins de Queiroz}

vanessa.queiroz@edu.sc.senai.br

Faculdade de Tecnologia SENAI

\section{Ricardo Kratz}

ricardok@edu.sc.senai.br

Faculdade de Tecnologia SENAI

Resumo: Este artigo apresenta o relato de um caso de aplicação de Aprendizagem Baseada em Projetos (ABP) a alunos do primeiro período de Engenharia Mecânica. Foi proposto, a partir da integração das unidades curriculares trabalhadas naquele período, o desenvolvimento de um brinquedo inclusivo para parque infantil destinado a pessoas com necessidades especiais (PNE). Foram desenvolvidos projetos de um balanço duplo para cadeirantes, um skate inclusivo, uma tirolesa para crianças com mobilidade reduzida e um balanço mecanizado. $\mathrm{O}$ método aplicado atingiu seu objetivo no que diz respeito tanto às atividades propostas em cada unidade curricular (Introdução à Engenharia Mecânica, Cálculo Diferencial e Integral I, Desenho Técnico I, Ciência Tecnologia e Sociedade, Álgebra Linear e Geometria Analítica) quanto no amadurecimento dos discentes, preparando-os para as próximas etapas acadêmicas, que incluem a fabricação de um protótipo do brinquedo projetado.

Palavras-chave: Metodologias ativas, PBL, Inclusão Social, PNE, Engenharia Mecânica, Projeto Integrador.

\section{Introdução}

A adoção de metodologias ativas de aprendizagem na engenharia vem sendo objeto de estudo em diferentes organizações (TEIXEIRA; SOUZA, 2018; FERREIRA et al., 2019) e é reflexo das transformações tecnológicas que ocorreram nos últimos anos e que afetam diretamente a atividade do engenheiro. A Aprendizagem Baseada em Projetos (ABP), ou Project Based Learning (PBL), é uma metodologia ativa de aprendizagem que busca a ambientalização do aluno na resolução de problemas, permitindo que ele tenha papel ativo no seu aprendizado ao mesmo tempo em que promove a interdisciplinaridade dos diferentes conteúdos curriculares. 


\section{corit:

Neste contexto, este artigo apresenta o relato de um caso de aplicação de ABP no primeiro período de Engenharia Mecânica, ou seja, para estudantes ingressantes na graduação, que trazem expectativas a respeito da profissão, bem como do curso que escolheram.

Segundo Guimarães (2003 apud BERBEL, 2011), os indivíduos são naturalmente propensos a realizar uma atividade por acreditarem que o fazem por vontade própria, porque assim o desejam e não por serem obrigados por força de demandas externas. Sendo assim, o objetivo da aplicação desta metodologia foi torná-los autônomos na resolução de um problema relevante para a sociedade e, assim, transformar esta expectativa em autorrealização, além de permitilhes desenvolver aptidões importantes em suas futuras carreiras: liderança, espírito de equipe, planejamento e capacidade de vender projetos e ideias.

A proposta foi estimular a difusão e o intercâmbio de técnicas e conhecimentos de engenharia aplicados à criação de um brinquedo de parque infantil, que promovesse a inclusão de crianças com deficiências físicas e/ou mentais, por parte de acadêmicos e professores do ensino de engenharia, por meio de aplicações práticas e da competição entre equipes.

\section{Procedimentos}

No início do período letivo, fevereiro de 2019, os alunos ingressantes foram introduzidos ao currículo e à estrutura do curso de Engenharia Mecânica. Neste momento, foi apresentada a metodologia adotada na instituição, na qual, a cada período letivo, é proposto um Projeto Integrador a ser desenvolvido pelos discentes com orientação dos professores. A ideia é integrar atividades das unidades curriculares para resolução de problemas de engenharia que tenham relevância para a sociedade.

As unidades curriculares abordadas no período referente a este estudo de caso foram: Introdução à Engenharia Mecânica, Cálculo Diferencial e Integral I, Desenho Técnico I, Ciência Tecnologia e Sociedade, Álgebra Linear e Geometria Analítica, e a Tabela 1 apresenta o índice da nota do Projeto Integrador aplicado à nota final de cada uma das unidades.

Tabela 1: Índices da nota do Projeto Integrador

\begin{tabular}{lc}
\hline \multicolumn{1}{c}{ Unidade Curricular } & Índice na Avaliação final \\
\hline Introdução à Engenharia Mecânica & $30 \%$ \\
Cálculo Diferencial e Integral I & $10 \%$ \\
Desenho Técnico I & $20 \%$ \\
Ciência Tecnologia e Sociedade & $20 \%$
\end{tabular}


A proposta, apresentada em março de 2019 para os alunos, foi desenvolver um protótipo de brinquedo modelado em software CAD, que pudesse ser usado em parques de Blumenau, cuja função primordial é a inclusão social, suprindo uma necessidade observada no município devido à falta de acessibilidade nas áreas públicas e urbanas.

No entanto, por se tratar de uma turma iniciante, optou-se por dividir o projeto em dois períodos, conforme Tabela 2.

Tabela 2: Etapas do Projeto Integrador

\begin{tabular}{ll}
\hline Período Letivo & Etapa do Projeto Integrador \\
\hline Primeiro & Projeto detalhado do brinquedo inclusivo \\
Segundo & Construção de protótipo (mínimo produto viável) \\
\hline
\end{tabular}

A partir de então, organizados em equipes de quatro pessoas e orientados pelos professores de cada unidade curricular, os alunos passaram a desenvolver as etapas programadas para o projeto conforme segue.

Etapa 1 - Pesquisa de anterioridade. (Atividade realizada na unidade curricular Introdução à Engenharia Mecânica).

Realização de pesquisa bibliográfica de anterioridade para definição do modelo e das características do produto a ser desenvolvido nas etapas de cálculos, simulações e projetos; registrando as informações coletadas durante as leituras e pesquisas na biblioteca e on-line em fichamentos e reescrevendo em forma de resumos e esquemas para reaproveitamento ulterior.

Etapa 2 - Discussão sobre a importância deste projeto no contexto social e realização de seminário sobre o tema. (Atividade realizada na unidade curricular Ciência, Tecnologia e Sociedade).

Etapa 3 - Desenvolvimento do croqui por equipes. (Atividade realizada na unidade curricular Desenho Técnico I).

\section{A' VIN QEEGC}


Etapa 4 - Análise do projeto executado selecionado. (Atividade realizada na unidade curricular Desenho Técnico I).

Realização de estudos, modelos e esboços prévios. Definição e esboço do modelo em folha padrão A4, A3, de forma que pudessem ser analisados: a forma do modelo, as dimensões e os materiais utilizados e, assim, partir para a elaboração do projeto pré-modelado em CAD.

Etapa 5 - Modelamento de partes do brinquedo inclusivo a partir de funções. (Atividade realizada na unidade curricular Cálculo Diferencial e Integral I).

Etapa 6 - Análise da viabilidade técnica. (Atividade realizada na unidade curricular Desenho Técnico I).

Etapa 7 - Levantamento dos itens a serem comprados para a etapa de construção do protótipo. (Atividade realizada na unidade curricular Desenho Técnico I).

Etapa 8 - Análise dos processos para fabricação em escala industrial. (Atividade realizada na unidade curricular Desenho Técnico I).

Etapa 9 - Projeto mecânico. (Atividade realizada na unidade curricular Desenho Técnico I), cujas atividades envolveram: modelamento em 3D; detalhamento em desenho técnico 2D; elaboração de lista de material, dimensionamento do modelo 3D; permitindo ao aluno desenvolver conhecimento em sistemas de tolerância baseado em normas técnicas; descrever, representar e apresentar resultados com precisão, estabelecendo relações entre conhecimentos específicos.

Etapa 10 - Técnicas de elaboração de relatório. (Atividade realizada na unidade curricular Ciência, Tecnologia e Sociedade).

Etapa 11 - Definição do movimento realizado pelo brinquedo algebricamente e matriz de deslocamento padrão para descrevê-lo. (Atividade realizada na unidade curricular Álgebra Linear e Geometria Analítica).

Etapa 12 - Entrega do relatório técnico e dos cálculos técnicos.

\section{A' VIN QEEGC}


Entrega de relatório de realização da pesquisa acadêmica do Projeto Integrador do Brinquedo

Inclusivo, contendo a descrição detalhada das etapas do projeto realizadas no semestre.

Etapa 13 - Elaborar apresentação PITCH.

Elaboração de um vídeo de 3 minutos apresentando o projeto e as soluções adotadas para os desafios apresentados.

Etapa 14 - Apresentação para a banca.

A Tabela 3 apresenta o cronograma de execução de cada etapa.

Tabela 3: Cronograma de execução do Projeto Integrador

\begin{tabular}{ccccc}
\hline & Mar & Abr & Mai & Jun \\
\hline Etapa 1 & & $\mathrm{x}$ & & \\
Etapa 2 & $\mathrm{x}$ & $\mathrm{x}$ & $\mathrm{x}$ & $\mathrm{x}$ \\
Etapa 3 & & $\mathrm{x}$ & & \\
Etapa 4 & $\mathrm{x}$ & $\mathrm{x}$ & $\mathrm{x}$ & $\mathrm{x}$ \\
Etapa 5 & $\mathrm{x}$ & $\mathrm{x}$ & $\mathrm{x}$ & $\mathrm{x}$ \\
Etapa 6 & $\mathrm{x}$ & $\mathrm{x}$ & $\mathrm{x}$ & $\mathrm{x}$ \\
Etapa 7 & $\mathrm{x}$ & $\mathrm{x}$ & $\mathrm{x}$ & $\mathrm{x}$ \\
Etapa 8 & $\mathrm{x}$ & $\mathrm{x}$ & $\mathrm{x}$ & $\mathrm{x}$ \\
Etapa 9 & $\mathrm{x}$ & $\mathrm{x}$ & $\mathrm{x}$ & $\mathrm{x}$ \\
Etapa 10 & $\mathrm{x}$ & $\mathrm{x}$ & $\mathrm{x}$ & $\mathrm{x}$ \\
Etapa 11 & $\mathrm{x}$ & $\mathrm{x}$ & $\mathrm{x}$ & $\mathrm{x}$ \\
Etapa 12 & & & & $\mathrm{x}$ \\
Etapa 13 & & & & $\mathrm{x}$ \\
Etapa 14 & & & & $\mathrm{x}$ \\
\hline
\end{tabular}

\section{Resultados e Discussão}

Foram desenvolvidos os projetos de quatro brinquedos inclusivos, apresentados em junho de 2019 para uma banca composta por um professor de álgebra, uma pessoa com necessidades especiais (PNE) atuante na sociedade e duas pessoas envolvidas com trabalhos para promoção da qualidade de vida de PNEs.

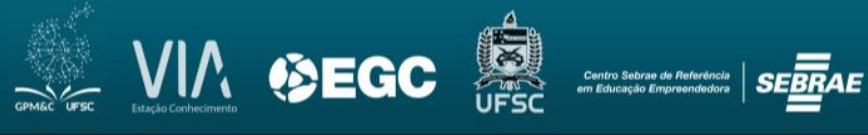


Balanço Duplo para Cadeirantes (Figura 1)

A proposta deste projeto foi de um balanço vai e vem, para uso por pessoas cadeirantes. No entanto, por ser um brinquedo inclusivo e não apenas um brinquedo acessível, ele foi projetado para ser utilizado tanto por pessoas portadoras ou não de necessidades especiais.

O balanço tem a função de suportar duas cadeiras de rodas uma de frente para a outra, ou ser utilizado por pessoas sem quaisquer deficiências, fazendo uma aproximação das crianças.

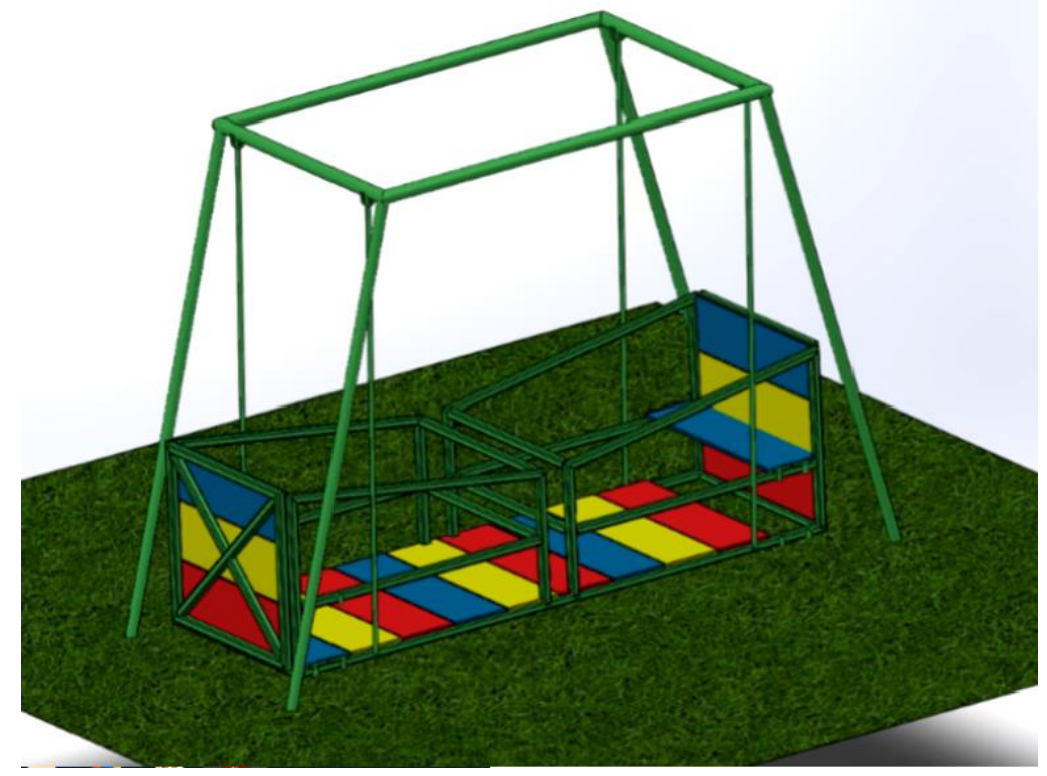

Figura 1: Balanço Duplo para Cadeirantes.

\section{Alfa Board (Figura 2)}

A ideia deste projeto foi, basicamente, adaptar um skate para que pessoas com algum tipo de deficiência possam andar nele. O skate adaptado tem como objetivo ser uma ferramenta de inclusão social para crianças e jovens com deficiência. Na visão dos alunos, a prática propiciaria a autonomia de crianças, jovens e adultos com deficiência física, auditiva, visual, intelectual ou múltipla.

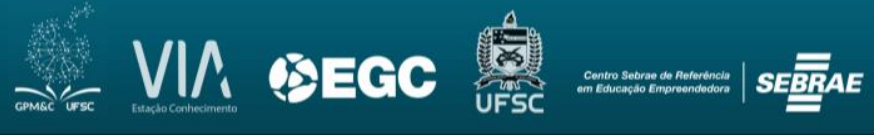




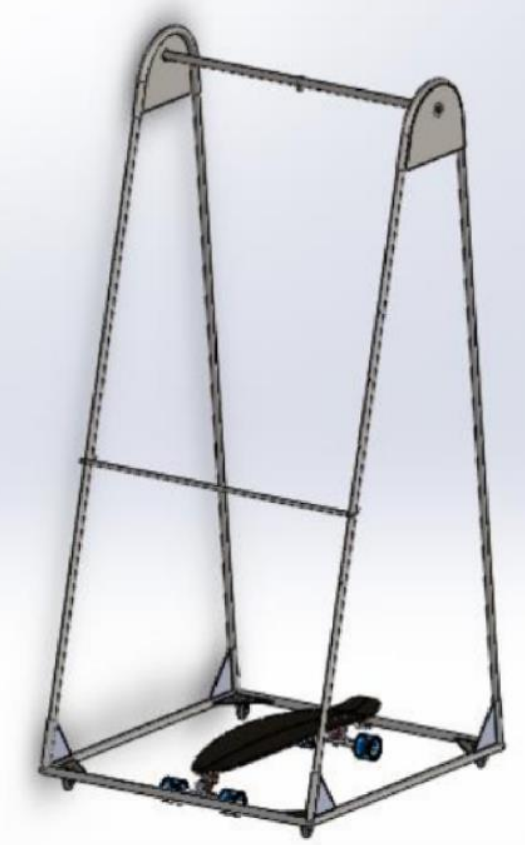

Figura 2: Alfa Board.

\section{Inclusão Radical (Figura 3)}

Neste projeto, foi idealizada a criação de uma tirolesa destinada, principalmente, à integração de crianças com mobilidade reduzida. Nas palavras dos alunos da equipe, a ideia "é levar uma brincadeira de forma mais dinâmica e com mais emoção para que estimule o espírito radical, e a integração de crianças deficientes com as não deficientes".

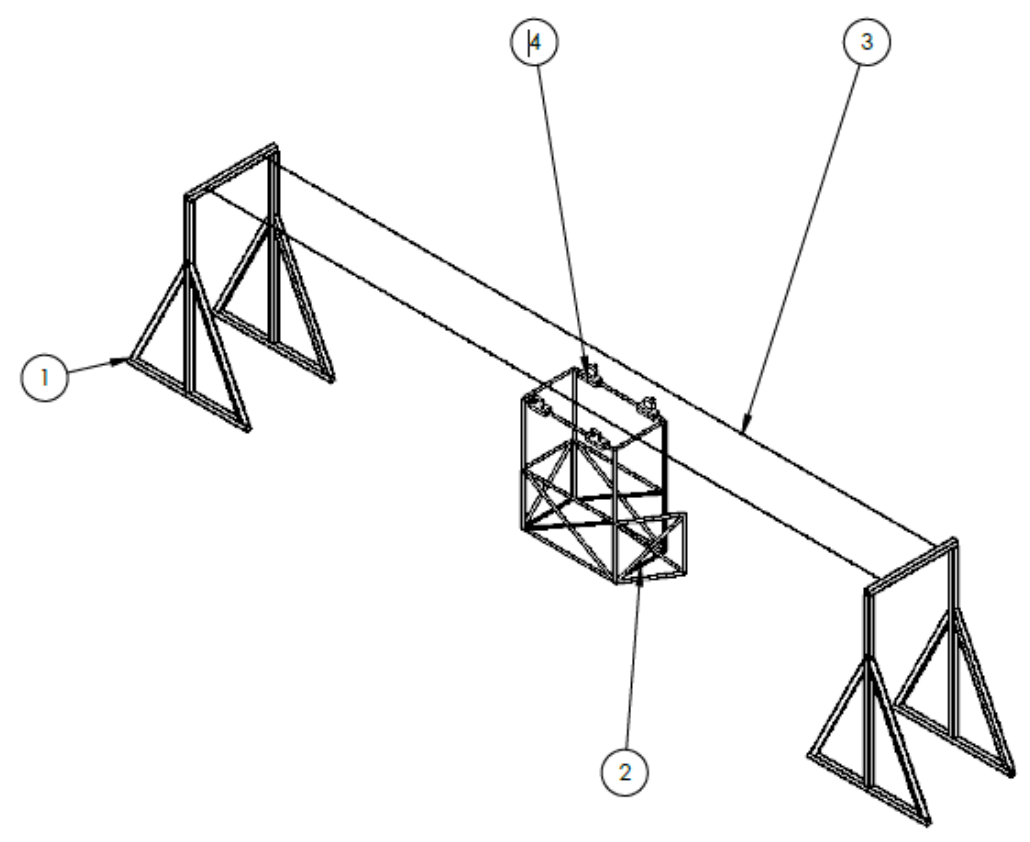

Figura 3: Inclusão Radical.

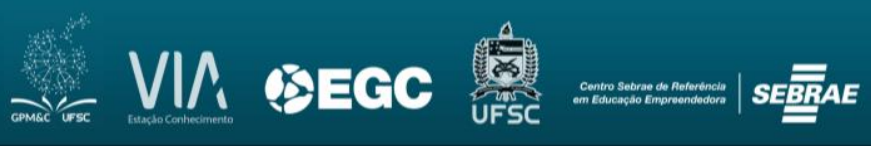




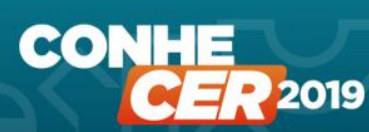

\section{Balanço Mecanizado (Figura 4)}

Trata-se do projeto de um balanço inclusivo, voltado especialmente para crianças usuárias de cadeira de rodas, que possa ser implementado com baixo custo e que permita a uma criança com livre movimento dos membros superiores utilizá-lo independentemente de ajuda externa e que continue proporcionando tanta diversão quanto um balanço convencional em seu movimento.

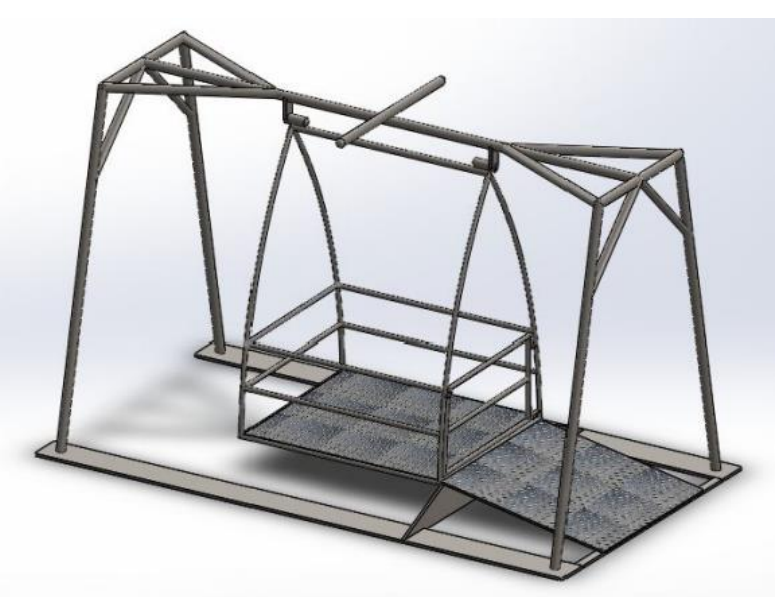

Figura 4: Balanço Mecanizado.

Durante a execução dos projetos, foi possível observar a evolução dos alunos no que diz respeito ao comprometimento com o tema, o que ocorreu na medida em que eles puderam se envolver através da pesquisa de anterioridade e de entendimento da necessidade do usuário final. Foi realizada uma conversa, organizada pela instituição de ensino, com uma pessoa com necessidades especiais (PNE) ativa na comunidade local, o que permitiu aos alunos uma percepção maior do contexto em que seus projetos estariam inseridos e o desenvolvimento da empatia pelo cliente a que deveriam atender.

Foi possível perceber que este sentimento, de efetivamente contribuir para a sociedade, desencadeou nos alunos um senso de responsabilidade e contribuiu para que eles se sentissem atores de uma mudança como futuros engenheiros.

Sendo assim, o método aplicado atingiu seu objetivo no que diz respeito tanto às atividades propostas em cada unidade curricular quanto no amadurecimento dos discentes, preparando-os para as próximas etapas acadêmicas, que incluem a fabricação de um protótipo do brinquedo projetado.

\section{AV VIN QEGC}




\section{Referências}

BERBEL, Neusi A. N. As metodologias ativas e a promoção da autonomia de estudantes. Semina: Ciências Sociais e Humanas, Londrina, v. 32, n. 1, p. 25-40, 2011.

FERREIRA, Marcos et al. Metodologias ativas de aprendizagem aplicadas no ensino da engenharia. CIET: EnPED, [S.1.], 2018. São Carlos, SP. Disponível em: http://cietenped.ufscar.br/submissao/index.php/2018/article/view/877. Acesso em: 07 ago. 2019.

TEIXEIRA, Clarissa S; SOUZA, Marcio V. de. Educação fora da caixa: tendências internacionais e perspectivas sobre a inovação na educação. v 4, São Paulo: Blucher, 2018. 